\title{
BMJ Open Risk selection in primary care: a cross- sectional fixed effect analysis of Swedish individual data
}

\author{
David Isaksson, ${ }^{1}$ Paula Blomqvist, ${ }^{2}$ Ronnie Pingel, ${ }^{1}$ Ulrika Winblad ${ }^{1}$
}

To cite: Isaksson $D$, Blomqvist $P$ Pingel $\mathrm{R}$, et al. Risk selection in primary care: a cross-sectional fixed effect analysis of Swedish individual data. BMJ Open 2018;8:e020402. doi:10.1136/ bmjopen-2017-020402

- Prepublication history for this paper is available online. To see these files, please visit the journal online (http://dx.doi. org/10.1136/bmjopen-2017020402).

Received 1 November 2017 Revised 29 May 2018 Accepted 22 August 2018

\section{ABSTRACT}

Objective To assess socioeconomic differences between patients registered with private and public primary healthcare centres.

Design Population-based cross-sectional study controlling for municipality and household.

Setting Swedish population-based socioeconomic data collected from Statistics Sweden linked with individual registration data from all 21 Swedish regions.

Participants All individuals residing in Sweden on 31 December 2015 ( $n=9851017$ ) were included in the study. Primary outcome measures Registration with private versus public primary healthcare centres.

Results After controlling for municipality and household, individuals with higher socioeconomic status were more likely to be registered with a private primary healthcare provider. Individuals in the highest income quantile were 4.9 percentage points $(13.7 \%)$ more likely to be registered with a private primary healthcare provider compared with individuals in the lowest income quantile. Individuals with 1-3 years of higher education were 4.7 percentage points more likely to be registered with a private primary healthcare provider compared with those with an incomplete primary education.

Conclusions The results show that there are notable differences in registration patterns, indicating a skewed distribution of patients and health risks between private and public primary healthcare providers. This suggests that risk selection behaviour occurs in the reformed Swedish primary healthcare system, foremost through location patterns.

\section{BACKGROUND}

Risk selection, meaning that healthcare providers try to attract patient groups with low health risks, is a concern in many healthcare systems. ${ }^{1-7}$ Risk selection of patients is a problem both in that it diverts from seeking efficiency in healthcare provision and that it undermines access to care for some patient groups. $^{8}$ In healthcare systems based on a multitude of health financers, risk selection is discussed foremost in relation to choices between different health funds or plans. ${ }^{149}$ In single-payer healthcare systems like the British National Health Service and the Nordic healthcare systems, patient selection cannot

\section{Strengths and limitations of this study}

The data set covers all individuals in Sweden, improving the external validity of the study.

- We combine socioeconomic data with individual data on primary care provider registration to create a data set that has not been analysed previously.

- The inclusion of smaller geographical unit as fixed effects makes it possible to reduce the effect of many possible confounders that are connected to geographical variation.

- A limitation is the lack of longitudinal data that would have created better opportunities to draw causal inferences.

occur among competitive insurance plans, since all citizens are automatically insured in one public fund but can still be a problem among healthcare providers. ${ }^{10-12}$ As open rejection of certain patients is typically not allowed in publicly financed healthcare systems, risk selection behaviour typically occurs through more indirect mechanisms, such as localisation of facilities, orientation of health services, targeted advertising, staffing language competence, physical availability of facilities, or interior decorating. ${ }^{51314}$ Risk selection behaviour among providers can be counteracted by reimbursement systems that compensate providers for high health risks, for instance with regard to age, health status or the socioeconomic status of patients. Previous studies indicate, however, that it is difficult to design reimbursement formulas in such a way that all types of health risks are eliminated. $^{2415}$ The introduction of market mechanisms in publicly financed healthcare systems, such as competition between providers, performance-related payments and patient choice systems, where the allocation of resources within the system follows the choices of patients, have been known to strengthen incentives for risk selection among providers. ${ }^{11}$ 
Risk selection among care providers has most often been studied in specialised and inpatient care. ${ }^{16-19}$ Some studies have documented that risk selection also occurs in primary care. ${ }^{20-24}$ Here, a main form of risk selection is the localisation of general practices, for instance, when general practitioners (GPs) seek to establish foremost in high-income areas where patients can be expected to be healthier, or in urban areas with a denser population base. ${ }^{21-2325}$ If this happens, access to care is reduced for patients with lower socioeconomic status and patients living in rural areas. It also means that health resources tend to be directed away from the areas where health needs are known to be higher. ${ }^{23} 2627$

In Sweden, combating inequities in health within the population has long been a central goal in health policy making. In order to further this goal, primary care has been organised since 1970 through an all-public system, based on primary healthcare centres (PHCCs) operated by regional health authorities called county councils. Operated by multiprofessional teams of nurses, GPs (typically between 4 and 6 at each centre) and paramedical professionals, the idea behind the centres is that they should be population based, that is, that each centre is responsible for the health outcomes of the population within their respective catchment areas. The centres provide a broad scope of primary care services including vaccination, maternal and child services and outreach programmes to implement preventive care. ${ }^{28}$ The primary care system changed in 2010, after the introduction of the so-called Primary Care Choice Reform, which gave private primary care providers the right to establish freely anywhere within a county and compete for public funding with public health centres if they offered a set of services required by the county council. ${ }^{21} 2829$ Offering patients a free choice to register with any provider, the new system led to a substantial increase in the share of private providers, which reached about $40 \%$ in 2016 . Based on the principles of free and neutral market competition, the reform deprived the county councils of the ability to plan care provision or allocate resources in accordance with public priorities; instead funding within the system became based on the number of registered patients and their visits. ${ }^{30}$ In 2017, an overwhelming majority of the new private health centres established in Swedish primary care after 2010 were operated by for-profit companies. ${ }^{21}$

The financial reimbursement systems vary between county councils, but they all have in common that capitation is used for at least $60 \%$ of the total reimbursement. In addition to capitation, most county councils also use a fee-for-service reimbursement. To moderate risk selection behaviour, capitation payments are often risk adjusted, which means that higher per capita reimbursement are paid for patients who can be expected to have more extensive care needs due to factors such as age, previous diagnoses and socioeconomic variables. ${ }^{31}$ There are two main types of risk adjustment payment formulas in Swedish primary care, Adjusted Clinical Groups (ACG) and Care Need Index (CNI). ACG is a risk adjustment model based on diagnoses for registered patients, while CNI is based on socioeconomic data of registered patients. The extent of risk adjustment differs between county councils. ACG adjustments range from $0 \%$ to $80 \%$ of capitation reimbursement, and CNI adjustments range from $1 \%$ to $20 \%$ of total capitation reimbursement.

Patient selection is also counteracted by the fact that all primary care centres must accept all patients who want to register; nor are providers allowed to set an upper limit of registered patients. Furthermore, providers are also not allowed to attract certain profitable patient groups by lowering the patient fee since a fixed fee of $0-30 €$ is used within all county councils.

One of the main criticisms of the reform was the concern that it would lead to unwanted risk selection through localisation. It was feared that the new private healthcare centres, given their profit orientation, would locate primarily in more prosperous areas, where health risks are known to be lower. ${ }^{30}$ Another concern was that different types of socioeconomic groups would make different registration choices, thereby contributing to a more stratified healthcare system. If socioeconomically stronger patient groups show a preference for private providers, the distribution of healthcare resources could become more skewed, offsetting the principle in Swedish health policy that health resources should be distributed solely on basis of medical needs. ${ }^{33}$ As noted in previous research, registration patterns can also be the result of risk selection behaviour among providers, for instance, in the form of targeted advertising, language competence among the staff or the physical accessibility of care facilities. ${ }^{14}$

In the present study, we investigate whether there is any empirical evidence that risk selection behaviour occurs in Swedish primary care. This is done by assessing if there are any socioeconomic differences between patients registered with private and public PHCCs. The analysis is based on a data set from 2016 that includes all Swedish individuals and provides information about their residence, registered PHCC, as well as a range of attributes such as age, education, income, employment and ethnicity. If the patients registered with private PHCCs are found to be different with regard to socioeconomic status, this can be seen as an indication of risk selection, either through localisation patterns or through, for example, targeted advertising. There is also the possibility that certain patient groups actively choose privately owned PHCCs, irrespective of their location or advertising. In either case, divergent patterns of patient registration between public and private PHCCs might lead to a more stratified primary care sector.

\section{METHODS}

\section{Design and material}

This is a population-based, cross-sectional study using individual level data from the total population register (Registret över totalbefolkningen), the income and tax register 
(Inkomst- och taxeringsregistret), The Swedish Register of Education (Utbildningsregistret) and the longitudinal integration database for health insurance and labour market studies (LISA). All individual level registers are maintained by the government agency Statistics Sweden and is updated at least yearly. The Swedish population registers are generally considered to have very high completeness and validity. ${ }^{34} 35$

Individual level data were linked to data owned by the 21 Swedish county councils containing information on which PHCC individuals were registered with. The linking was done by by Statistics Sweden using a deterministic linkage model with personal identification numbers as identifiers. The personal identification numbers were replaced with serial numbers before the authors were given access to the data to provide anonymity. Furthermore, public information such as addresses and ownership of PHCCs was gathered from each county council's web page by the authors and linked to the individual data using a deterministic linkage model with PHCC name as the identifier. The data set thereby makes it possible to locate at which PHCC each Swedish individual is registered.

\section{Study population}

All individuals residing in Sweden on 31 December 2015 $(n=9851017)$ were included in the study. Several of the variables did not contain data for individuals aged 0-18 years. Thus,when analysing these variables, only the remaining $\sim 7.6$ million individuals were included in the analyses.

\section{Variables}

Individual level variables were selected based on previous research suggesting an association between the variable and differences in health needs. See table 1 for a list of all individual-level variables.

\section{Individual-level outcome}

The form of ownership of the PHCC at which an individual is registered was the main outcome. It was coded 1 if an individual was registered with a privately owned PHCC, and 0 if an individual was registered with a PHCC with a public ownership.

\section{Individual-level variables}

Income was included since it has a well-established relationship with health needs. ${ }^{36}{ }^{37}$ Income was measured as disposable household income per household member over the age of 18 years. Household income per adult household member was used instead of individual income to better capture the actual economic situation of the individual. We studied income as both a continuous variable and a categorised variable based on the quantiles of income distribution in each municipality.

Region of birth contained eight categories: Sweden, Nordic countries, EU28, Eastern Europe, Asia, Africa, South America and North America plus Oceania. Individuals born in Eastern Europe, South America, Asia and Africa are more likely to have refugee status, associated

\begin{tabular}{|c|c|}
\hline Variable & Description \\
\hline Individual & $\begin{array}{l}\text { Personal identification number to identify } \\
\text { individual. }\end{array}$ \\
\hline Household & $\begin{array}{l}\text { Variable to identify individuals belonging } \\
\text { to the same household. }\end{array}$ \\
\hline Year & Year of birth. \\
\hline Country of birth & Country of birth (grouped into clusters). \\
\hline $\begin{array}{l}\text { Income per adult } \\
\text { in household }\end{array}$ & $\begin{array}{l}\text { Disposable yearly income per household } \\
\text { member in SEK. }\end{array}$ \\
\hline Level of education & $\begin{array}{l}\text { Categorical variable measuring highest } \\
\text { level of finished education. }\end{array}$ \\
\hline Sickness benefits & $\begin{array}{l}\text { Binary variable indicating if the individual } \\
\text { receives sickness benefit or work injury } \\
\text { compensation. }\end{array}$ \\
\hline Employment & $\begin{array}{l}\text { Binary variable indicating if the individual } \\
\text { is employed or not. }\end{array}$ \\
\hline $\begin{array}{l}\text { Labour market } \\
\text { programme }\end{array}$ & $\begin{array}{l}\text { Binary variable indicating if the individual } \\
\text { receives income from labour market } \\
\text { policy measures. }\end{array}$ \\
\hline Early retirement & $\begin{array}{l}\text { Binary variable indicating if the } \\
\text { individual receives early retirement } \\
\text { income, disability payment or activity } \\
\text { compensation. }\end{array}$ \\
\hline Registered PHCC & $\begin{array}{l}\text { The PHCC an individual is registered } \\
\text { with. }\end{array}$ \\
\hline
\end{tabular}

SEK, Swedish krona.

with having lower socioeconomic status and higher healthcare needs ${ }^{38}$ compared with the rest of the population. For individuals born in the Nordic countries, EU28, North America and Oceania, however, we do not expect to find any significant differences.

Level of education was measured using seven categories: less than 9 years of education, primary education $\geq 9$ years, secondary education $\leq 2$ years, secondary education $\geq 3$ years, higher education $<3$ years, higher education $\geq 3$ years and doctoral studies. We included level of education in the analysis since it has been found to correlate with health needs; that is, a lower level of education is associated with higher health needs. ${ }^{39}$

Sickness benefits, unemployment compensation, labour market compensation or early retirement compensation were all binary variables included in the analysis. All these variables are likely to correspond with higher expected health needs. ${ }^{40}$

\section{Household and PHCC level variables}

A household identifier was linked to each individual. At the PHCC level, the municipality was used as a control variable and ownership status was used in calculating the individual-level outcome. Thus, we are not primarily interested in differences between municipalities but rather differences between individuals registered with private and public PHCCs within a municipality. 


\section{Statistical analysis}

Descriptive statistics comparing the distributions of the variables within ownership were reported as proportions and counts for all variables.

We used a linear probability model to analyse the probability of selecting private PHCC conditional on socioeconomic variables. The model assumes that the relationship between the binary outcome and dependent variables can be formulated as:

$$
\operatorname{Pr}(\text { Private }=1 \mid \mathrm{X}=x)=x^{\prime} \beta
$$

where $\mathrm{x}$ denotes a vector of variables and $\beta$ the coefficients for the variables, that is, individual level variables and dummy variables for municipality level fixed effects. We are then able to estimate the proportion of individuals registered with a private PHCC by each category of each socioeconomic variable, models $1-8$. In model 9 , all variables were included in a single regression model. All regression analyses included municipality fixed effects, and we calculated robust SEs that took into account clustering at the household level and heteroscedasticity.

The main reason for using the linear probability model is interpretability. One can argue that actual differences in proportions that describe the magnitude are of a greater policy relevance than ORs, which would be the case if we were to use logistic regression. Also, since it is not rare to be registered with a private PHCC (45\%), ORs cannot easily be approximated as a relative risk which further complicates the interpretation.

Three arguments are often made against the linear probability model: the model may give invalid predicted probabilities smaller than 0 or larger than 1 ; heteroscedasticity; and non-normality. The first argument is related to the coefficients of the regression model. Many invalid predicted probabilities would of course suggest a bad model. However, this was not the case in our study, and if the probabilities are in the range $(0.2-0.8)$, predictions from a linear probability model and a logistic model are comparable. Furthermore, our interest lies in estimating difference in proportions, that is, averages, not predicted probabilities of individuals. The last two arguments concern the inference, which is, due to the very large sample size, a minor issue. ${ }^{41}$

In the regression models, apart from analysing all individuals in a total population model, we analysed two different samples separately. In the first sample, we excluded individuals living in municipalities with $<1$ private PHCC and individuals living in municipalities with $<1$ public PHCC. In the second sample, we excluded all individuals living in municipalities with $<0.4$ private PHCCs per 10000 inhabitants as well as individuals living in municipalities with $<0.4$ public PHCCs per 10000 inhabitants. The reason for using these samples is that all included individuals in the samples can be considered to have good availability to alternative PHCCs, that is, they have a practical possibility to choose either a private or a public PHCC.
When performing the statistical analysis, Stata V.15.0 was used for calculating descriptive data and regressions. R V.3.4.3 was used for creating the graphs and figures.

\section{Patient and public involvement}

The Regional Ethical Review Board of Uppsala, Sweden, which has representation from the public, approved the study. Thus, the aim, method and study design were examined by lay members, representing patients and the public. The results will be presented at national meetings and conferences aimed towards the public and patients.

\section{RESULTS}

Table 2 shows socio-economic comparisons between patients registered with private and public PHCCs. The table gives an indication of marked socio-economic differences between patients registered with private and public PHCCs.

Higher education and income is associated with a higher probability of being registered with a private PHCC. Individuals who receive sickness or occupational injury benefits, have early retirement benefits, or take part in a labour market programme are more likely to be registered with a public provider. We did not detect any clear pattern when it comes to country of birth. A reason behind this could be that immigrants are not evenly spread out over the country but mainly located in larger cities where private PHCCs are more prevalent. Since the results in table 2 do not control for municipal or county clusters, the differences between patients registered with public and private PHCCs could be an effect of geographic variation and the prevalence of private PHCG. Private PHCCs are not evenly distributed over the country but are concentrated mainly in urban areas. ${ }^{21}$ In general, individuals residing in urban areas have different socioeconomic characteristics than the rest of the country, such as a higher level of education and a higher percentage of individuals born outside of Sweden.

When investigating mean socioeconomic differences between different PHCCs visually, it became evident that the variation is relatively large. Figure 1 shows a boxplot of median adult income per household for individuals registered with different PHCCs, grouped by county council. Both the spread of income and share of private PHCCs vary between county councils, showing the necessity of controlling for cluster effects. Furthermore, it is clear that the relationship between median income for registered patients and whether the PHCC is privately or publicly owned is not perfect. However, the results reveal that privately run PHCCs have registered patients with a higher median income.

Table 3 shows the different fixed effect regression analyses when controlling for municipalities and households. In general, the results reveal that patients registered with a private healthcare centre on average have higher socioeconomic status. Household income 
Table 2 Two-way table showing descriptive statistics for all dichotomous variables grouped into ownership of registered PHCC for an individual

\begin{tabular}{|c|c|c|c|c|c|c|}
\hline & \multicolumn{6}{|c|}{ Ownership of registered PHCC } \\
\hline & \multirow{2}{*}{$\begin{array}{l}\text { Public } \\
\text { Freq }\end{array}$} & \multirow[b]{2}{*}{$\%$} & \multirow{2}{*}{$\begin{array}{l}\text { Private } \\
\text { Freq } \\
\end{array}$} & \multirow[b]{2}{*}{$\%$} & \multirow{2}{*}{$\begin{array}{l}\text { Total } \\
\text { Freq }\end{array}$} & \multirow[b]{2}{*}{$\%$} \\
\hline & & & & & & \\
\hline \multicolumn{7}{|l|}{ Income per adult in household } \\
\hline 1st quantile & 1193458 & 64.2 & 664967 & 35.8 & 1858425 & 100 \\
\hline 2nd quantile & 1169742 & 63.0 & 688477 & 37.0 & 1858219 & 100 \\
\hline 3rd quantile & 1151842 & 62.0 & 706330 & 38.0 & 1858172 & 100 \\
\hline 4th quantile & 1135202 & 61.1 & 722962 & 38.9 & 1858164 & 100 \\
\hline 5th quantile & 1101803 & 59.3 & 755943 & 40.7 & 1857746 & 100 \\
\hline \multicolumn{7}{|l|}{ Country of birth } \\
\hline Sweden & 4930816 & 62.2 & 2994546 & 37.8 & 7925362 & 100 \\
\hline Eastern Europe & 148660 & 63.7 & 84887 & 36.3 & 233547 & 100 \\
\hline North America or Oceania & 20031 & 53.7 & 17287 & 46.3 & 37318 & 100 \\
\hline Africa & 107174 & 64.0 & 60246 & 36.0 & 167420 & 100 \\
\hline Asia & 325153 & 61.3 & 205328 & 38.7 & 530481 & 100 \\
\hline EU28 outside Nordic countries & 174296 & 58.5 & 123582 & 41.5 & 297878 & 100 \\
\hline Nordic countries & 141401 & 60.4 & 92891 & 39.6 & 234292 & 100 \\
\hline South America & 35680 & 55.1 & 29080 & 44.9 & 64760 & 100 \\
\hline \multicolumn{7}{|l|}{ Level of education } \\
\hline Primary education $<9$ years & 57305 & 69.2 & 203735 & 30.8 & 661040 & 100 \\
\hline Primary education $\geq 9$ years & 613698 & 62.9 & 361299 & 37.1 & 974997 & 100 \\
\hline Secondary education $\leq 2$ years & 1070678 & 64.0 & 602744 & 36.0 & 1673422 & 100 \\
\hline Secondary education $\geq 3$ years & 1033271 & 61.5 & 647943 & 38.5 & 1681214 & 100 \\
\hline Higher education $<3$ years & 613404 & 58.8 & 429375 & 41.2 & 1042779 & 100 \\
\hline Higher education $\geq 3$ years & 840214 & 56.7 & 642871 & 43.3 & 1483085 & 100 \\
\hline Doctoral studies & 44246 & 55.4 & 35680 & 44.6 & 79926 & 100 \\
\hline Employment & 2709464 & 60.0 & 1807667 & 40.0 & 4517131 & 100 \\
\hline Sickness benefits & 355269 & 60.7 & 229538 & 39.3 & 584807 & 100 \\
\hline Early retirement & 235904 & 65.5 & 124250 & 34.5 & 360154 & 100 \\
\hline Labour market programme & 195394 & 65.3 & 103677 & 34.6 & 299071 & 100 \\
\hline Age $>75$ years & 576871 & 65.9 & 298712 & 34.1 & 875583 & 100 \\
\hline Total & 5883211 & 62.0 & 3607847 & 38.0 & 9491058 & 100 \\
\hline
\end{tabular}

The percentages shown are row percentages.

per adult is divided into quantiles. The results from the total population model 1 show that the higher the income, the more likely an individual is to be registered with a private primary care provider. An individual with a household income in the highest quantile is 4.9 percentage points more likely to be registered with a private PHCC compared with an individual in the same municipality with a household income in the lowest quantile. Based on the continuous income variable, we have calculated the mean difference in annual disposable household income per adult household member to roughly 17584 SEK when controlling for municipality. This is a significant difference considering the mean disposable income of 260000 SEK.
The findings also show that education has a significant effect on the likelihood of being registered with a private PHCC. The higher the education level, the more likely an individual is to register with a private PHCC. The only exception is for individuals with a doctoral degree who are less likely to register with a private PHCC compared with other people with higher education. However, individuals with a doctoral degree are still 3.9 percentage points more likely to register with a private PHCC compared with individuals with less than 9 years of education.

Table 3 also indicates that country of birth has a distinguishable influence on the likelihood of registering with a private or public PHCC. People who are born in 


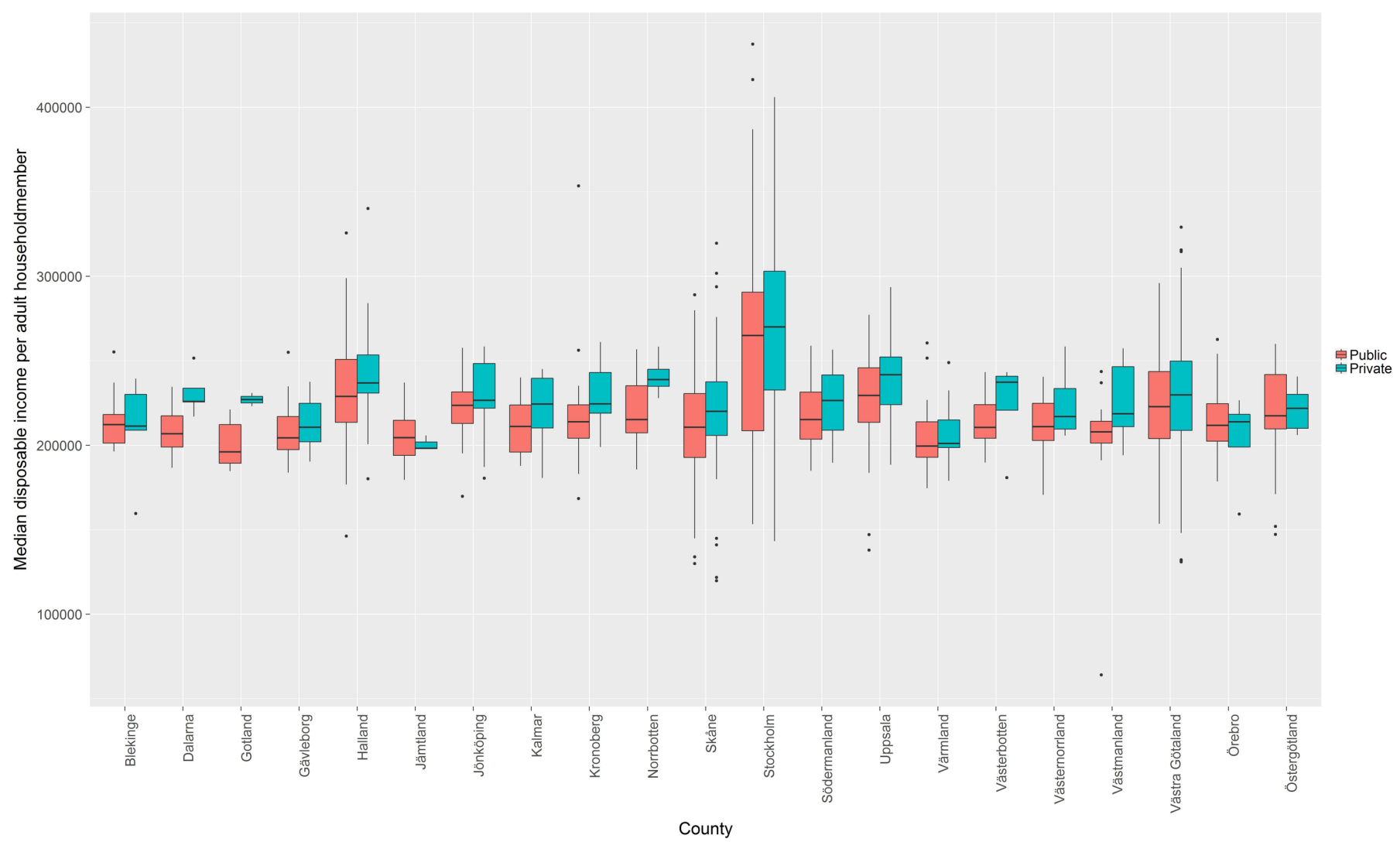

Figure 1 Boxplot of median income for individuals registered with a certain PHCC. The y-axis shows median disposable income for people registered at a PHCC. The $\mathrm{x}$-axis is a categorical variable grouping the PHCC by what county they are located in.

North America or Oceania are more likely to register with a private PHCC than people born in Sweden. The difference between people born in Sweden and people born in other Nordic countries or the European Union is relatively small. Conversely, a large difference is seen for people born in Eastern Europe, Asia and Africa compared with native Swedish people. The likelihood for a person born in Africa to register with a private PHCC is 5.6 percentage points less than an individual in the same municipality who is born in Sweden. In other words, the likelihood of a Swedish born individual registering with a private PHCC is $37.1 \%$, while the corresponding figure for an individual born in Africa is $31.5 \%$, that is, $15.6 \%$ less likely to register with a private PHCC.

An individual who is employed has a 2.6 percentage point higher likelihood of registering with a private PHCC compared with an individual without employment. Correspondingly, people who receive benefits from early retirement or are in labour market programmes are, respectively, 1.9 and 2.0 percentage points less likely to register with a private PHCC. Individuals over the age of 75 years are also less likely to register with a private PHCC, on average 1.8 percentage points less likely than those under the age of 75 years. We found that people who receive sickness benefits are 1.4 percentage points more likely to register with a private PHCC. This is the only result that did not support the risk selecting behaviour hypothesis. We will return to this result in the discussion.

Finally, in the full model, we constructed a multiple fixed regression model, controlling for all independent variables in the previous models. As expected, the coefficients are generally smaller since many of the included socioeconomic variables are correlated. However, the same general pattern is still visible. Individuals with higher income and education that are born in Sweden or the Nordic countries are more likely to be registered with a private PHCC. The effects of employment, early retirement and participation in labour market programmes are now very small.

When individuals living in municipalities without alternative PHCCs to choose from were excluded (samples 1 and 2), the results show the same trends but with a slightly higher magnitude. To further assess the robustness of the results, a density plot was generated (see figure 2).

The density plot in figure 2 reveals that the likelihood of registering with a private PHCC is consistently based on disposable income, that is, up until a certain level of income an individual is more likely to register with a public PHCC. After that level, individuals are more likely to register with a private PHCC.

To assess the consistency of the results across the country, we plotted three variables grouped by municipality. Only 150 out of 290 municipalities are included in 


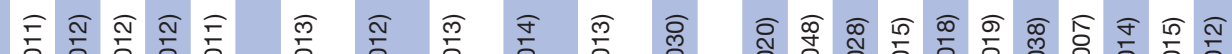

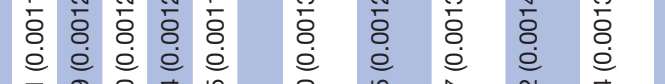

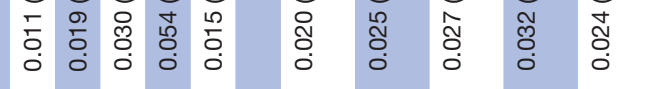

¿.

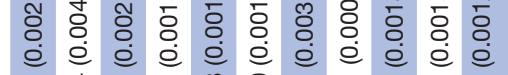

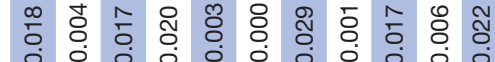
e $\doteq$ e

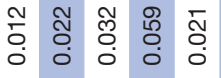

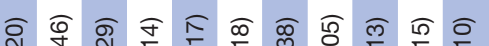

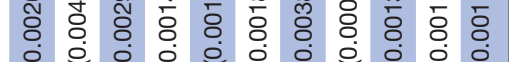
๙

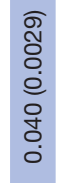

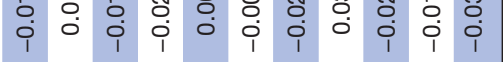

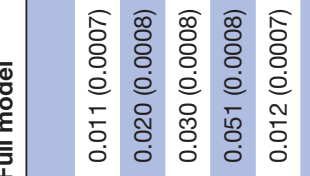

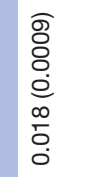

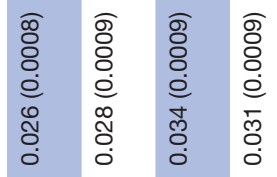

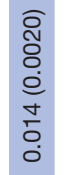

ติ

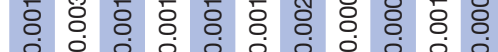

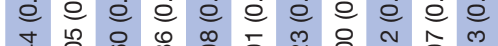

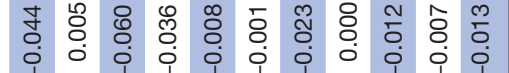

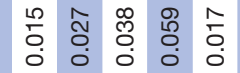

0
0
0
0
0
0

西

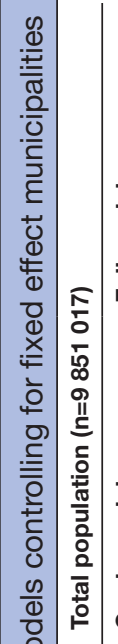

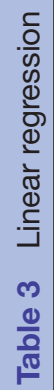

\section{ฮิ \\ 0.000}

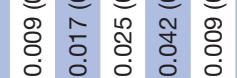

$\begin{array}{lllll}0 & 0 & 0 & 0 & 0\end{array}$

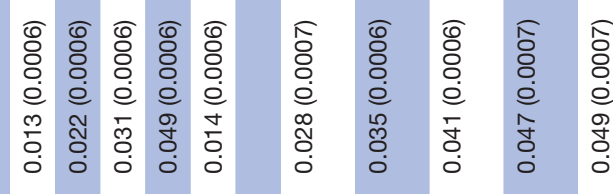

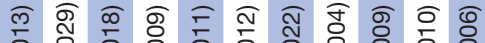

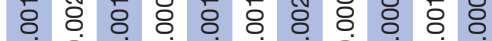

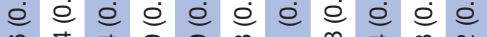

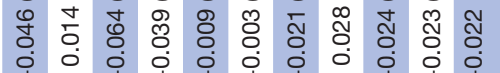

$\widehat{\infty}$
$\stackrel{\infty}{0}$
0
0
0
$\vdots$
0

สิ

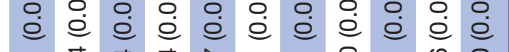

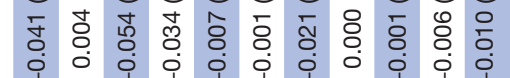

동

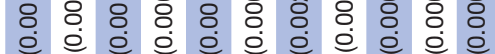
ปै

흥

$\frac{0}{\frac{0}{0}}$

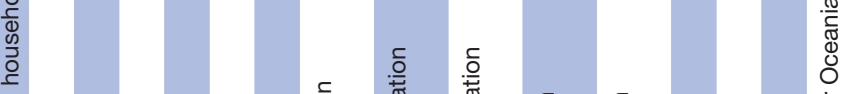

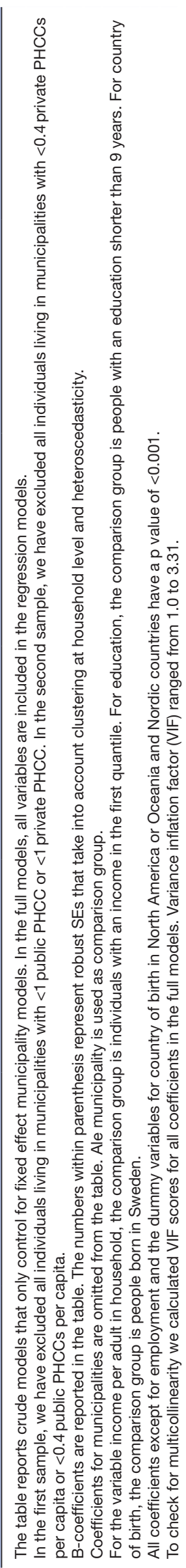




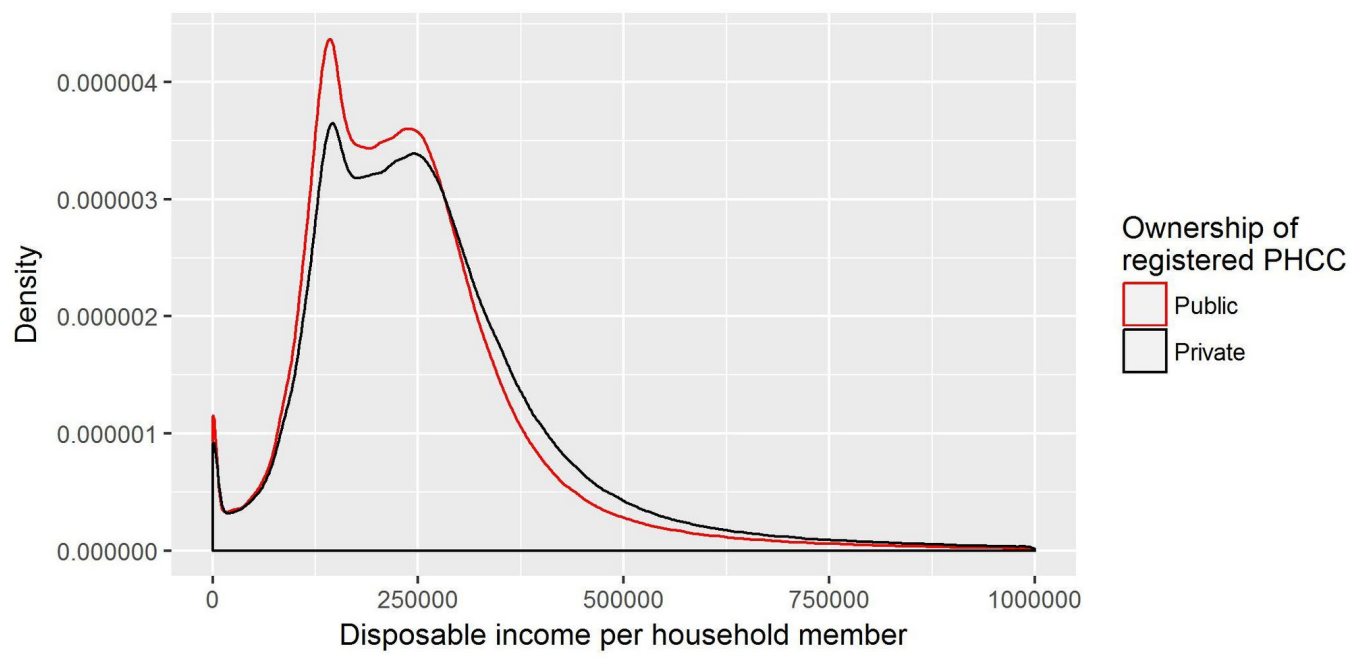

Figure 2 Density plot over disposable household income per adult and choice of PHCC.

these plots since the other 140 municipalities have only either public or private providers in their geographical areas. Mean values for all individuals registered with a public PHCC was calculated for the variables: employment, income and education. We then calculated the mean of the individuals registered with private PHCCs in that municipality and plotted the percentage differences from the municipality means (see figure 3 ).

As expected, we find some differences between municipalities. However, in roughly 120 out of 150
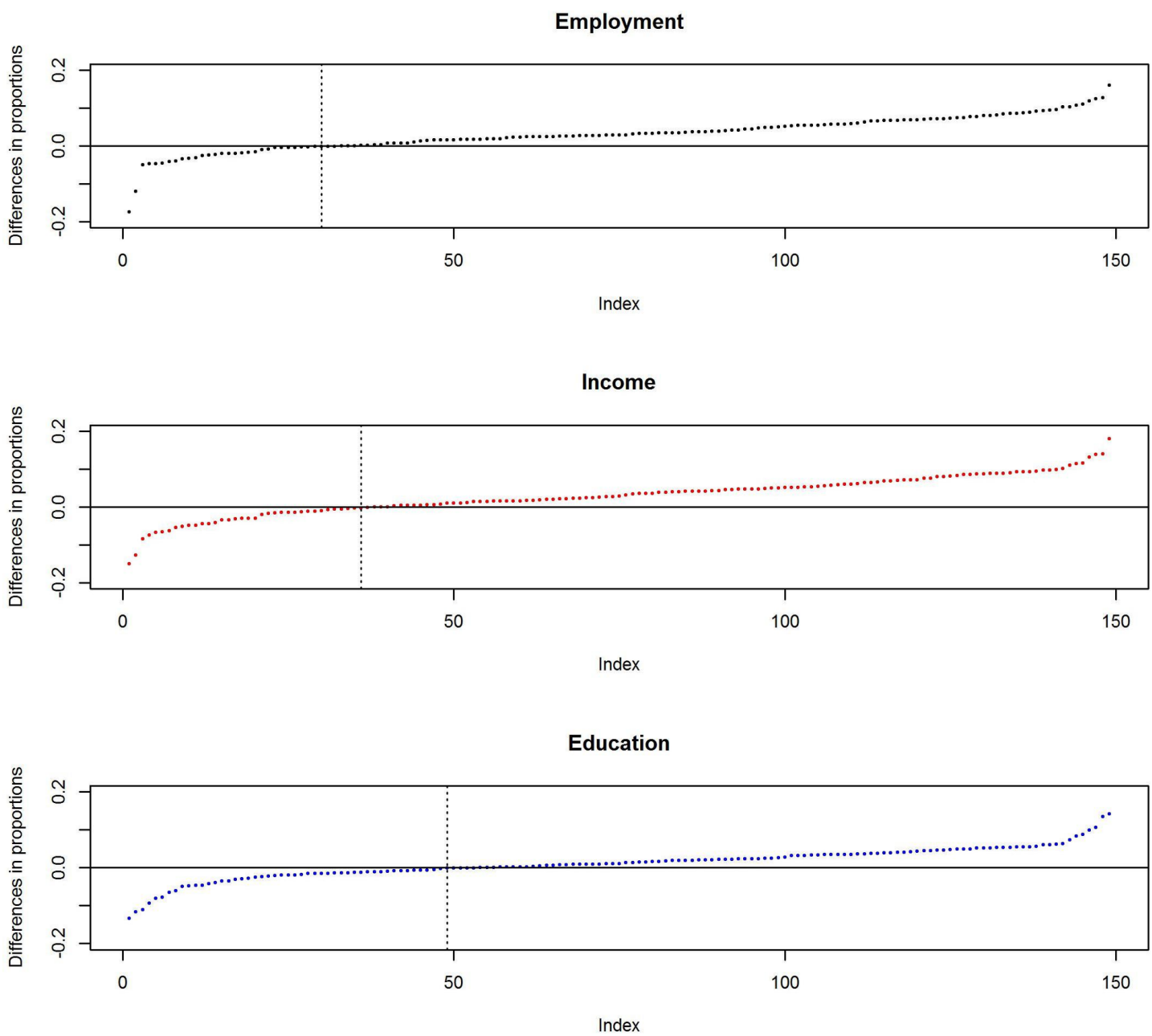

Figure 3 Plots over employment, income and education differences in proportions for individuals registered with private versus public PHCCs grouped based on municipality. 
municipalities, individuals registered with private PHCCs are employed to a higher degree than individuals registered with a public PHCC. Income seems to have the highest consistency over municipalities while we find a larger variation for education.

\section{DISCUSSION}

The main research question posed at the outset of the paper was whether there was any evidence of risk selection in Swedish primary care after the 2010 patient choice reform. The empirical analysis, investigating whether there are any socioeconomic differences between individuals registered at private and public healthcare centres, indicates that this may be the case. The result of the analysis shows that there were several differences between the two groups. Most notably, individuals registered with a private primary healthcare provider were shown to have significantly higher income levels and levels of education than those registered at public PHCCs. In addition, it was also demonstrated that individuals born in Africa and Asia, most of whom are likely to have come to Sweden as refugees, are less likely to register at a privately owned health centre. A less expected result was that individuals who receive sickness benefits were more likely to register with a private healthcare centre. A possible explanation for this pattern, which contradicts our hypothesis that individuals with low socioeconomic status would be less likely to register with private health centres, could be the finding in previous studies that patients who are frequent visitors to healthcare providers are more likely to make active choices. ${ }^{42}$ In the Swedish context, making an active choice often implies leaving the 'old' public health centre to which individuals previously were referred on basis of residence address for a newly established private PHCC.

Taken together, these results point to individuals who could be expected to have higher health needs due to socioeconomic characteristics like education, income levels and country of birth being less likely to register with a private healthcare provider than individuals with lower expected health needs. It should be noted that this result, which indicates that some risk selection behaviour may indeed occur on the part of private health providers, was obtained despite the fact that the financial reimbursement systems in all counties are risk adjusted, typically on basis of factors such as age, employment status and income. If there had been no risk adjustment, it is likely that differences between public and private health centres would have been even more pronounced.

In addition to the risk selection behaviour by the providers, individual choices may have added to the pattern of skewed distribution of health risks between public and private care providers observed. As noted in the background section, a skewed distribution of health risks can occur also through the choices of patients themselves. High-income earners, or the better educated, are more likely to actively choose a private care provider on their own accord, thereby creating an uneven distribution of health risks. Thus, provider localisation and individual choices are highly intertwined. Private PHCCs seem to locate in more affluent areas with higher economic status. ${ }^{21}$ Since proximity is one of the most important factors for choosing a healthcare provider, ${ }^{43} 44$ this creates a socioeconomically unequal distribution between patients registered with private and public PHCCs. If socioeconomically stronger patient groups primarily register with the new private providers, the distribution of healthcare resources might be skewed, leading to fewer resources for more care-needing patients at public primary care providers. Thus, there is a clear risk of equity being undermined by providers establishing in socioeconomically more prosperous areas-a development that is reinforced by patients' own choices.

\section{Strengths and limitations}

The main strength of the study is the combination of data sets that make it possible to link information about the socioeconomic status of individuals in Sweden to their residence and combine this with information about what primary care provider they are registered with. Another strength are the controls used for the smaller geographical unit, which are the municipalities. This implies that it is possible to reduce the effect of many possible confounders that are connected to geographical variation of both the dependent and independent variables.

A limitation in the study is the lack of longitudinal data. With longitudinal data, it would have been possible to discern changes in registration pattern after an individual's socioeconomic status had changed or the ownership of a PHCC had changed from private to public or vice versa. Furthermore, the study could have been improved by including additional background variables such as number of years immigrants have resided in Sweden, patient diagnosis and comorbidity, and data on what year the PHCCs were established.

Another limitation is the fact that it is not possible through the study to determine with certainty whether the observed differences in patient registration patterns between public and private care providers depend on risk selection behaviour on part of the providers, for instance through geographical location, or the choices of patients themselves, where some patient groups may have a preference for private care providers. A final limitation is the lack of data for specific country of birth outside of Sweden which probably stifles the differences we can identify.

\section{Implications for research and policy}

The results of the study have several important implications, both for the research field and health policy making. An important contribution to the research field is made 
in that the undertaken study provides empirical evidence of a phenomenon that hitherto has only rarely been investigated systematically: risk selection in primary care in publicly financed healthcare systems. Also, we argue that the results of the study could have policy implications for countries with a similar healthcare system as Sweden, among them the other Nordic countries and other countries that emphasise the importance of equity in access to healthcare. The results in the paper highlights the need to regularly assess evidence of risk selection and modify risk adjustments in order to assure effective and equitable use of healthcare resources. Moreover, the findings of the study points to a need for further research to establish what the most common forms of risk selection behaviour in primary care are and to what extent they can be mediated by regulation and financial incentives.

The implications for policy making are clear, particularly in countries where healthcare provision is based on values such as solidarity and equity in access but where competition between care providers is seen as desirable. Specifically, the results of the study indicate that reforms involving free establishment of commercially oriented providers in primary care might be problematic from an equity point of view, even in systems where the funding remains public or, if such reforms are implemented, that it is important to carefully design financial reimbursement formulas so that health risks are adjusted for. The findings in the Swedish case indicate that risk adjustment in capitation payments on the basis of factors like age, employment status and income is not enough to prevent risk selection behaviour among providers. The difficult task for health policy makers seeking to market-orient publicly funded healthcare systems, then, is to design reimbursement systems that discourage risk selection but do not hamper competition, innovation and free provider choice for patients.

Acknowledgements We would like to thank all Swedish county councils for providing registration data. We gratefully acknowledge financial support from the Swedish Research Council for Health, Working Life and Welfare (FORTE). We would also like to thank the reviewers for their constructive comments.

Contributors DI, PB and UW conceptualised and designed the study. DI and RP performed data management and statistical analyses. DI wrote the first draft of the paper, and all authors were involved in revising the paper. All authors read and approved the final version of the paper.

Funding The study was funded by the Swedish Research Council for Health, Working Life and Welfare, FORTE (No. 2011-1137).

Competing interests None declared.

\section{Patient consent Not required.}

Ethics approval The study was approved by the Regional Ethical Review Board in Uppsala (Dnr 2012/238). An amendment to the original application was approved on 4 November 2015.

Provenance and peer review Not commissioned; externally peer reviewed. Data sharing statement No additional data are available.

Open access This is an open access article distributed in accordance with the Creative Commons Attribution Non Commercial (CC BY-NC 4.0) license, which permits others to distribute, remix, adapt, build upon this work non-commercially, and license their derivative works on different terms, provided the original work is properly cited, appropriate credit is given, any changes made indicated, and the use is non-commercial. See: http:// creativecommons.org/licenses/by-nc/4.0/.

\section{REFERENCES}

1. Brown J, Duggan M, Kuziemko I, et al. How Does Risk Selection Respond to Risk Adjustment? New Evidence from the Medicare Advantage Program. Am Econ Rev 2014;104:3335-64.

2. Schokkaert E, Dhaene G, Van de Voorde $C$. Risk adjustment and the trade-off between efficiency and risk selection: an application of the theory of fair compensation. Health Econ 1998;7:465-80.

3. van Kleef RC, van de Ven WP, van Vliet RC. Risk selection in a regulated health insurance market: a review of the concept, possibilities and effects. Expert Rev Pharmacoecon Outcomes Res 2013;13:743-52.

4. Van de ven W, Ellis RP. Chapter 14 Risk adjustment in competitive health plan markets. Handb Heal Econ 2000;1:755-845.

5. Barros PP. Cream-skimming, incentives for efficiency and payment system. J Health Econ 2003;22:419-43.

6. Koning P, Heinrich CJ. Cream-Skimming, Parking and Other Intended and Unintended Effects of High-Powered, PerformanceBased Contracts. Journal of Policy Analysis and Management 2013;32:461-83.

7. Ellis RP. Creaming, skimping and dumping: provider competition on the intensive and extensive margins. J Health Econ 1998;17:537-55.

8. Luft HS, Miller RH. Patient Selection in a Competitive Health Care System. Health Aff 1988;7:97-119.

9. Pope GC, Kautter J, Ellis RP, et al. Risk adjustment of Medicare capitation payments using the CMS-HCC model. Health Care Financ Rev 2004;25:119-41.

10. Rice N, Smith PC. Capitation and risk adjustment in health care financing: an international progress report. Milbank $Q$ 2001;79:81-113.

11. van de Ven WP, Beck K, Van de Voorde C, et al. Risk adjustment and risk selection in Europe: 6 years later. Health Policy 2007;83(23):162-79.

12. Puig-Junoy J. Managing risk selection incentives in health sector reforms. Int J Health Plann Manage 1999;14:287-311.

13. Newhouse JP. Patients At Risk: Health Reform And Risk Adjustment. Health Aff 1994;13:132-46.

14. Bickman L, Dokecki PR. Public and private responsibility for mental health services. Am Psychol 1989;44:1133-7.

15. Greß S, Delnoij DM, Groenewegen PP. Managing primary care behaviour through payment systems. In: Saltman RB, Rico A, Boerma W, eds. Primary Car in the Driver's Seat?. Maidenhead, United Kingdom: Open University Press, 2006:184-200.

16. Ellis RP, McGuire TG. Hospital response to prospective payment: moral hazard, selection, and practice-style effects. $J$ Health Econ 1996;15:257-77.

17. Berta P, Callea G, Martini G, et al. The effects of upcoding, cream skimming and readmissions on the Italian hospitals efficiency: A population-based investigation. Econ Model 2010;27:812-21.

18. Cheng TC, Haisken-DeNew JP, Yong J. Cream skimming and hospital transfers in a mixed public-private system. Soc Sci Med 2015;132:156-64.

19. van de Ven WPMM, van Kleef RC, van Vliet RCJA. Risk Selection Threatens Quality Of Care For Certain Patients: Lessons From Europe's Health Insurance Exchanges. Health Aff 2015;34:1713-20.

20. Kantarevic J, Kralj B. Risk selection and cost shifting in a prospective physician payment system: Evidence from Ontario. Health Policy 2013;23:249-57

21. Isaksson $D$, Blomqvist $P$, Winblad $U$. Free establishment of primary health care providers: effects on geographical equity. BMC Health Serv Res 2016;16:1-15.

22. Haynes R, Lovett A, Sünnenberg G. Potential Accessibility, Travel Time, and Consumer Choice: Geographical Variations in General Medical Practice Registrations in Eastern England. Environment and Planning A 2003;35:1733-50.

23. Gravelle $H$, Sutton $M$. Inequality in the geographical distribution of general practitioners in England and Wales 1974-1995. J Health Serv Res Policy 2001;6:6-13.

24. Weiner JP, Starfield BH, Steinwachs DM, et al. Development and application of a population-oriented measure of ambulatory care case-mix. Med Care 1991;29:452-72.

25. Rosenthal MB, Zaslavsky A, Newhouse JP. The geographic distribution of physicians revisited. Health Serv Res 2005;40:1931-52.

26. Dixon A, Le Grand J. Is greater patient choice consistent with equity? The case of the English NHS. J Health Serv Res Policy 2006;11:162-6. 
27. Goddard M. Access to health care services--an English policy perspective. Health Econ Policy Law 2009;4(Pt 2):195-208.

28. Burström B, Burström K, Nilsson $\mathrm{G}$, et al. Equity aspects of the Primary Health Care Choice Reform in Sweden - a scoping review. Int J Equity Health 2017;16:1-10.

29. Anell $A$, Glenngård $A H$, Merkur $S$. Sweden health system review. Health Syst Transit 2012;14:1-159.

30. Fredriksson M, Blomqvist P, Winblad U. The trade-off between choice and equity: Swedish policymakers' arguments when introducing patient choice. J Eur Soc Policy 2013;23:192-209.

31. lezzoni LI. Risk Adjustment for Measuring Health Care Outcomes. Chicago, III: Health Administration Press, 2013.

32. Burstrom B. Looking to europe - will swedish healthcare reforms affect equity? BMJ 2010;340.

33. Daniels N. Just Health Care. Cambridge: Cambridge University Press, 1985.

34. Carlsson AC, Li X, Holzmann MJ, et al. Neighborhood socioeconomic status at the age of 40 years and ischemic stroke before the age of 50 years: A nationwide cohort study from Sweden. Int J Stroke 2017;12:815-26.

35. Åberg MA, Torén K, Nilsson M, et al. Nonpsychotic Mental Disorders in Teenage Males and Risk of Early Stroke: A Population-Based Study. Stroke 2016;47:814-21.
36. Martinson ML, Teitler JO, Plaza R, et al. Income disparities in cardiovascular health across the lifespan. SSM Popul Health 2016;2:904-13.

37. Frijters P, Haisken-DeNew JP, Shields MA. The causal effect of income on health: evidence from German reunification. $J$ Health Econ 2005;24:997-1017.

38. Porter M, Haslam N. Predisplacement and postdisplacement of refugees and internally displaced persons. J Am Med Assoc 2005;294:610-2.

39. Sundquist K, Malmström M, Johansson SE, et al. Care Need Index, a useful tool for the distribution of primary health care resources. $J$ Epidemiol Community Health 2003;57:347-52.

40. Hollederer A. Unemployment, health and moderating factors: the need for targeted health promotion. J Public Health 2015;23:319-25.

41. Cheung YB. A modified least-squares regression approach to the estimation of risk difference. Am J Epidemiol 2007;166:1337-44.

42. Dixon A, Robertson R, Appleby J, et al. Patient choice - how patients choose and how providers respond. London, United Kingdom: The Kings Fund, 2010.

43. Birk HO, Gut R, Henriksen LO. Patients' experience of choosing an outpatient clinic in one county in Denmark: results of a patient survey. BMC Health Serv Res 2011;11:262.

44. Varkevisser M, van der Geest SA, Schut FT. Assessing hospital competition when prices don't matter to patients: the use of timeelasticities. Int J Health Care Finance Econ 2010;10:43-60. 